$\xi=-1$

\title{
Post Graduate Business Education: Tracing through Different Learning Methods in Controversial Subjects Teaching
}

\author{
Dr. Meena J. Panikker*, Dr. Muhamad Shafi* \\ School of Management Studies, National Institute of Technology Calicut, Kerala, India, Pin. 673601
}

\begin{abstract}
'Business, Government and Society' is one of the subjects for the Management curriculum at most of the B-Schools and the National Institute of Technology Calicut is also one such. The subject includes two components - business and government, and business and society; the teaching of this subject involves great challenges primarily due to the nature of the subject itself and also because of the diversity of the student group. The subject predominantly deals with:

a) How the society influences the ethics of business.

b) How the strategies of the government are linked with business.

These issues need to be highlighted because India is a pluralistic society and hence the great variation in the degree of the awareness of the issues under discussion within the scope of this subject as well as the huge dissimilarity in their level of acceptance of certain elements pertaining to these issues, especially so, because they belong to the different communities. The students for the Management programme at the National Institute of Technology Calicut come from various communities across India. This study explores how the students respond to the different methods of learning namely, conventional learning, collaborative learning, and cooperative learning and also analyses which of these methods promote a healthy cognitivism in the students. The study was conducted among ten students (five from Kerala and five from non-Kerala) across five different batches over the years, 2012-2017. It was noted that through conventional learning there was hardly any change in the students' personal ideologies which were often in conflict with the ideologies of the other students. It was also noted that it was through collaborative and cooperative learning methods that the students were able to diffuse their personal political ideologies in the larger interests of the state. It was also noted that through the method of cooperative learning for the teaching of this subject, that the cognitive development in the students was encouraged. The relevance of including such a subject in the curriculum was thus established and the goals of teaching the subject were also fulfilled because it helped in creating better student awareness and also traced a better way for the students to arrive at solutions for the problems concerned.
\end{abstract}

Keywords: Business, Government and Society, Cooperative Learning, Cognitivism, Education, Pluralism

\section{Introduction}

Education is increasingly becoming challenging in this century because, often in classroom teaching, a strict shift between the ideologies of the students and that of the teacher (not personal ideology but, what is expected- the ideal) is noticed. In business education at the collegiate level, there are often subjects which may pose a question on the intentions of the state, especially so, if it poses a challenge to the existing socio-politico- cultural ideals of the individual in a democracy. Refraining from the inclusion of such subjects in the curriculum cannot be recommendable as it becomes important for the sustenance for a healthy educational experience within the scope of the democracy itself. To quote from Badri, "[C]ontroversial issues are important in themselves and to omit informing about and discussing them is to leave a wide and significant gap in the educational experience of young people ". There is no rigid border separating society and governance in a practical view and the degree of this overlap is vital in deciphering the role, depth and the nature of business in that geographical area. This issue is even more complex when there are cultural divides in a country that is essentially pluralistic that is also a democracy like the case of India. The BBC reports that there are 3,000 castes and 25,000 sub castes in India, each related to a specific occupation. Though, these caste divisions were ini- tially based on the occupational status of the people here, which influenced the role of business and government in the society, the schemes of education, empowerment, inclusive development as put forth by the Government overtimes has changed the scenario, though the fact that the possibility of some societies in India still maintaining the rigidity along many levels cannot be discounted. The reasons for the same could be multiple. It is generally agreed that the customs, beliefs, and practices of the various groups might be in slight opposition to the strategies of the all- inclusive- government. That is to say, India's pluralism is its greatest asset and also its greatest curse. "Cultural pluralism remains India's strongest card and its best defence against attempts to wreck its integrity or weaken its national structure from inside and outside. "So, it is obvious that there are likely to be clashes of interest among the different groups, be it religious, political, economic and the like. Dealing with such topics is very challenging because often, the teacher feels powerless in dispiriting most of the students who take it on a personal level. To quote from S. Philipott et.al. "These classroom controversies arise because the core of the issues concern individual personal values. So even though the discussion ... about how laws are created, centered on historical events, the underlying value struggle about government intervention is one that continues today. "Most often, the governmental policies and people's interests could also be on different planes. Though there are 
many studies related to the teaching of controversial subjects in school and also on the need to include controversial topics related with business, society and government in the curriculum there are no studies that have come up in the area that deals with the challenges of teaching controversial subjects like "Business, Government and Society" for the Management students in a national level institute in India. This opens up the huge scope for this study which tries to explore how many students at the post graduate level are aware about such issues that could be termed as controversial and what notions do they have about these, if they are already aware. This study also tries to prove what methods the teacher adopts in classroom teaching and how has these methods influenced the students to think in the benefit of the state. Enough care must also be taken that the teacher avoids all four possible stances, namely, 'denial', 'privilege', 'avoidance' and 'balance' resultant of their own biased political views on the controversial issues discussed so that the main purpose of including these topics in the curriculum is eventually effectuated. In the view of the modern democratic nation, multiple perspectives to the same issue are encouraged for the purpose of better examining "the social, political and economic structures" within the society and this is one reason why such topics should be mandatorily included in the postgraduate management curriculum. We have taken up two main issues (two case studies are given in each category) that may be termed as controversial in the subject "Business, Government and Society" included in the curriculum for the Management students at the National Institute of Technology Calicut for the study:

\subsection{Public Purpose and Private Property:}

In a democratic country the margin between the public property and private property is very narrow though there are specific rules for this divide. Cultural and familial bonding to an ancestral property is so rigid that people in India become extremely self-centered to allow the state to acquire a piece of land that is in their individual / familial possession for the common benefit of the nation. Often, the state can take only nominal steps to ensure this acquisition of land. In India, the industrial growth had always been impeded by the land acquisition issues. Though this has led to the Land Acquisition Act of 1894 (Old Land Acquisition Act) being replaced by the Right to Fair Compensation and Transparency in Land Acquisition, Rehabilitation and Resettlement Act 2013 (New Land Acquisition Bill ), it worried the social activists as they felt that the farmers' rights (India is basically an agrarian society) and also the industry advocates who regarded the New Act as more expensive and time consuming.

\subsubsection{Tata Motors in Singur :}

On October 3, 2008, Tata Motors withdrew its plans of car manufacturing unit at Singur, West Bengal India following the wide spread protests from the local farmers. The people claimed that their land had been acquired under questionable circumstances and this experience epitomized the challenges faced due to the land acquisition issues .

\subsubsection{Special Economic Zones in India:}

In 2007, violent clashes between the police and the local people erupted in Nandigram, West Bengal over the acquisition of 14,000 acres of land, mostly agricultural, for the setting up of a Special Economic Zone (SEZ). The project was a joint venture by the state- owned West Bengal Industrial Development Corporation and Indonesia's Salim group. The protests were because of two reasons- one is that the lands were settled for a below- market price and the other is that this acquisition displaced thousands of farmers

\subsection{Foreign Direct Investment and National Sovereign- ty:}

For the developing countries like India, Foreign Direct Investments are always an integral part of their business plan.

\subsubsection{0\% FDIs in Single and Multi Brand Retail in India:}

The current government seeks India's development only through economic impetus and as such, plans to bring in 100\% FDI (Foreign Direct Investment) in India invites lots of controversies. This stance is seen as a threat to the national sovereignty especially so, if it is implemented in major strategic structures like railways, defence and retail. The controversy lies around the extent of dependability on the foreign (developed countries) economic interests. This was also a case in itself.

\subsubsection{The Walmart- Massmart merger as an illustration:}

It is to be noted that the Walmart- Massmart merger in South African economy has influenced the development and the employment ratio, but a small amount of national sovereignty is unconditionally compromised.

Table 1: Awareness about issues of 'Public Purpose and Private Property' and 'Foreign Direct Investment and National Sovereignty'

\begin{tabular}{|l|l|l|l|l|}
\hline Academic Year & Tata Motors in Singur & SEZ, Nandigram & $100 \%$ FDIs & $\begin{array}{l}\text { Walmart- Massmart Mer- } \\
\text { ger }\end{array}$ \\
\hline $2012-13$ & $85 \%$ & $75 \%$ & $60 \%$ & $45 \%$ \\
\hline $2013-14$ & $86 \%$ & $72 \%$ & $65 \%$ & $40 \%$ \\
\hline $2014-15$ & $88 \%$ & $70 \%$ & $68 \%$ & $35 \%$ \\
\hline $2015-16$ & $71 \%$ & $70 \%$ & $34 \%$ \\
\hline
\end{tabular}

From the table above, it could be understood that all the students were not aware about the issues listed though as management students, it was important for them to know these above mentioned cases from the business perspective. It may also be noted that the figures corresponding to the awareness about the Tata Motors case is almost consistent throughout the batches because, the case had attracted enough media attention, but this is not so in the case of SEZ, Nandigram. It was found that most students were aware about the atrocities and violence that the place had been witness to but, not many were aware about the impacts or necessity of SEZ from the business perspective. There is a gradual increase over the years in the awareness of FDIs in India, especially so, because of the immediacy of the issue (there was a change in the political leadership in India in 2014). Not more than $45 \%$ peo- ple were aware about the Walmart- Massmart merger and the issues related with it - the figures are also found to be gradually decreasing over the years. This may indicate that the students were not much aware of the international business trends happening in the third world countries. The factors for this trend could be proximity and a prejudiced notion. Proximity indicates that students are concerned about what is happening in their homeland and the prejudiced notion points to the fact that the students who were studied were considering only the business changes in the developed countries as important. 


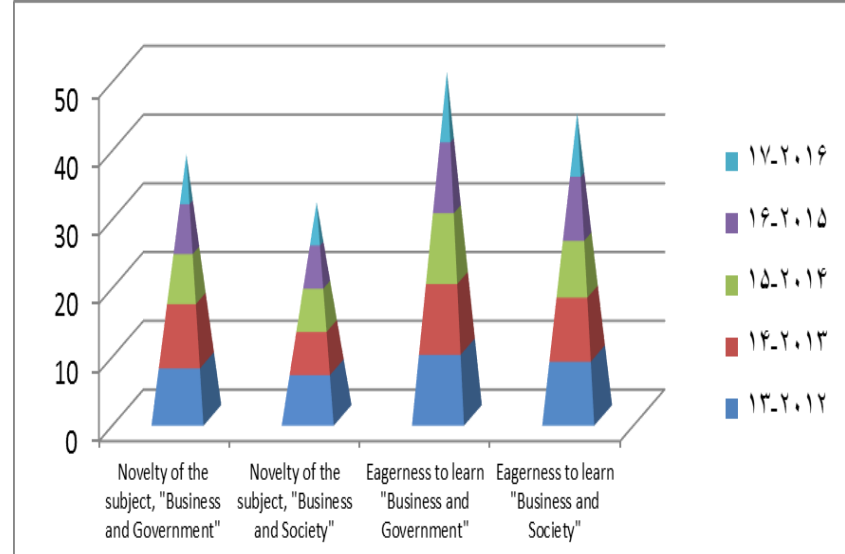

Fig. 1: Stacked pyramid chart on the Students' Subject Knowledge and Eagerness to Learn

The above figure shows that the students were not much aware about the subjects and they displayed high eagerness to know more about it. It has to be noted that on an average scale there were 8 students in the initial year of the study who were not aware that 'Business and Government' would be a part of the Management Education curriculum which increased to 9 in the following year and the numbers remained consistent throughout the following years on 7 . That is, the majority of the students were not aware that such a subject for the Management curriculum would be included and hence, their preparedness on the issues could not certainly be ascertained. This increases the task of the teacher.

\section{Experimental details}

Most often, subject teachers handling controversial topics face the dichotomous issue of convincing the students about an existing problem at the one hand and of influencing them to understand that economic progress and security at the national level at the other hand which is far more important than the cultural sentiments affecting the decision of the mob on the other hand. We analyse how to effectively teach "Business, Government and Society" to the students of the National Institutes at the post graduate level keeping the teacher's personal ideology aside. This study is based on five batches of Management Students in NITC (from a period of 2012-17) and the sample size is divided into two. In each batch the students' population is divided into Kerala and NonKerala group and the sample size is maintained as 10. Classroom teaching always involves different methods. We opted for three methods namely, the conventional learning method- the lecture method, the collaborative learning method and the cooperative learning method and we also studied which method was able to affect the cognitive development of the students in a positive way.

\subsection{Lecture Method:}

A total of 10 hours were dedicated to the teaching of the above mentioned four controversial issues. In the conventional oral lecture method and the not-so-conventional oral lecture - discussion method, it was found that the students' responses were vague and the participation was also found to be low. In the survey, it was analysed that more than $70 \%$ of the total students irrespective of the fact that they belong to North India/ South India did not participate wholly. Most of them were passive listeners. The students who participated actively were either those students who were very active, displaying an extrovert attitude or those who had some idea about the subject. Indubitably, this assessment is also related to the factors like memory retention power and intelligence capacities apart from the students' psychological perception of a particular subject and the depth of desired theoretical knowledge. Nevertheless, it was obvious that the lecture method was not much successful as it did not influence those students who were neutral to the issues under discussion/ who had little subject knowledge. It is worth noting that the student activities like the possibility of clarification of students' notes with their partner and other student engagement activities into traditional learning methods were not voluntarily introduced by the teacher to make this learning method active. This was done so, to understand the relationship between the students' participation and cognitive levels of understanding. Hardly any change was observed in their attitudes, prejudices and pre- lecture notions about the topics and most often, some of them even had interests which were detrimental to the interests of the state influenced by their cultural paradigms and individual experiences.

Table 2: Reported Effect Size in Conventional Learning

\begin{tabular}{|c|c|}
\hline Academic Areas & Effect Size \\
\hline Tata Motors & 0.25 \\
\hline SEZ, Nandigram & 0.35 \\
\hline 100\% FDIs & 0.28 \\
\hline Walmart- Masmart Merger & 0.15 \\
\hline
\end{tabular}

The above table illustrates the effect size and it is evident that the majority of the students were not personally motivated to change their initial ideas on these four issues. Hence, it could be concluded that the conventional method was not a great success in motivating the students and helping them on the axis of cognitive development.

\subsection{Collaborative Method:}

The students were asked to discuss the issue in groups of two and the study materials were provided to them after giving them a brief idea about the topic. Group assignments on different perspective of the same issue were given to them so that they could understand the concept in a better way. The students were asked to prepare a detailed list of the advantages and disadvantages of the scheme from a business perspective. But, it was found that $30 \%$ of the students completed the assignment only for the sake of assessments and they were not much convinced about the topics, on which awareness was lesser, under discussion. However, it was noted that those students who were passive in the conventional learning method were slightly active in collaborative learning method. Johnson, Johnson and Smith and Springer et.al. have found through their studies that the students' academic achievement, quality of interpersonal interactions, self- esteem, positive attitude development perceptions of greater social support, improved drastically by collaborative learning method .

Table 3: Reported Effect Size in Collaborative Learning

\begin{tabular}{|c|c|}
\hline Academic Areas & Effect Size \\
\hline Tata Motors & 0.45 \\
\hline SEZ, Nandigram & 0.50 \\
\hline 100\% FDIs & 0.35 \\
\hline Walmart- Masmart Merger & 0.28 \\
\hline
\end{tabular}

The above table shows that their active participation did improve and they were able to answer in a better way some academic questions related with management theories and the cases mentioned. In the post graduate education, it is insisted that the students spend an average of at least 2 hours for studying outside the classroom for every one hour of in- class study. This requirement was also fulfilled since they had to complete their class assignments.

\subsection{Cooperative Method:}

The main focus was to shift from the teacher- centric classrooms and to increase individual accountability at the level of the students. In cooperative learning, the students were divided into larger groups. Positive interdependence was seen to have encouraged 
the students' participation - even those students who were weak in the subject and were reserved in their behavioural traits improved tremendously. A brief about the topic was provided- the problem was specified and then the groups were asked to discuss and debate, question and re-question themselves till they got the answer. Case study methods and analysis of group projects (including the projects that they undertook in collaborative learning) were provided as tasks and that each group had a mixture of students belonging to Kerala and outside Kerala was meticulously monitored. Instructions were given that the solution / outcome should be convincing to all the members of the group. It was found that there was only one possible answer to the problem since the crowd in each group was diverse and that solution was in the benefit of the state, especially because it was taken from the business perspective of India's development. The students were able to set aside their personal prejudices towards an issue, because if they did not do that the solutions were hard to be found.

It should be noted that in all these above teaching methods, care was taken that a brief idea of the topic was given in a neutral way and that the teacher's personal ideology did not in any way influence the students. How to use the technique of cooperative learning in the cognitive approaches to the teaching of the subject "Business, Government and Society" effectively was also analysed. Mainly three techniques were used for the process: Case study, project evaluation and reciprocal teaching. In the Case study method, the students were provided with four case studies-

a) Tata Nano Entry and Exit in West Bengal

b) Special Economic Zone in India: Public Purpose private Property

c) $100 \%$ FDIs in Single and Multi-Brand Retail in India

d) Wall Mart- Massmart Merger

The projects that the students undertook related with particular topics in collaborative learning were given for evaluation in cooperative learning. Thus, the students were analysing their own projects and assignments and this helped them understand the topic in a better and social inclusive way. It also boosted them to be their own self critics and aided them in developing a better outline of the objectives and outcomes of the issue concerned.

Table 4: Reported Effect Size in Cooperative Learning

\begin{tabular}{|c|c|}
\hline Academic Areas & Effect Size \\
\hline Tata Motors & 0.65 \\
\hline SEZ, Nandigram & 0.60 \\
\hline 100\% FDIs & 0.50 \\
\hline Walmart- Masmart Merger & 0.45 \\
\hline
\end{tabular}

Each group was given a particular aspect of the same study and they were asked to explain to the rest of the students what they understood and why they reached a particular conclusion. This way, the reciprocal teaching ensured that different perspectives of the same topic reached everybody equally and appropriate discussions ensued. Also, since this was the last technique used, it was also noticed that there were no different perspectives formed other than that of the state's perspectives on each of these issues, even though, the student group consisted of students belonging to various cultures. So, they were able to understand that culture-specific solutions might not be always apt in the context. Table 4 illustrates the effect size in the various academic areas under discussion in cooperative learning method.

\section{Results and discussion}

This study was done to analyse the effectiveness and the different ways of the cooperative learning method in influencing the cognitive learning of the students and also to know if this learning method is the best suited for the teaching of a subject which is in the parameter of contradicting ideas. Though the sample size was small and limited to just four cases, the data analysed showed that (refer Tables 2-4) there was a considerable improvement in the
Effect size as we moved from Conventional learning methods to Cooperative learning. In the first case of Tata Motors, the progress was $80 \%$ from conventional learning to collaborative learning and an addition of $33.33 \%$ in cooperative learning. In the case related to SEZ Nandigram, the variations were from $43 \%$ to an addition of $20 \%$. In $100 \%$ FDIs, the Effect size increased from 25\% in cooperative learning to a further $43 \%$ in cooperative learning; and in Walmart- Masmart Merger, the Effect size was $87 \%$ in cooperative learning which further rose to $61 \%$ in cooperative learning. Therefore, the highest progress in collaborative learning was recorded in Walmart- Masmart merger case and Tata Motors case whereas the highest in cooperative learning was recorded in Walmart- Masmart Merger and 100\% FDIs cases.

\section{Conclusions}

It should be remembered that both these cases - the WalmartMasmart Merger and 100\% FDIs cases were the ones where the students' had displayed low awareness levels. It could hence be assumed that employing the methods of cooperative and collaborative learning for areas where the students require a better exposure would suit the best purpose of leaning. Considering their progress in the Walmart- Massmart Merger, it could also be argued that it is through the Collaborative learning method that the initial stage of cognitivism is achieved. This initial cognivitism is further boosted by the technique of cooperative learning. This could be stated because in cooperative learning, the task is well comprehended, there is a greater retention of memory and the students' responses are eloquently mapped prompted by the higher degree of motivation. There is also the significant factor of social desirability in the need for accommodating the various concerns related with the plurality of the group members to arrive at a possible amicable solution with respect to the cases given for study that is encouraged through cooperative learning and hence it becomes cognitive in all aspects.

To sum up, Collaborative learning and Cooperative learning are the best methods to teach the subject "Business, Government and Society" as the Management students themselves were able to resolve lots of controversial issues and see their own ideological/ political differences melt away in the benefit of the state's view. Such a view is most essential because these students are the future of India and they are a part of the promise that India upholds in its future business ventures. Hence, it is indeed crucial that the students need to be motivated on the cognitive axis of learning so that better awareness, better understanding and tactful long-term solutions to the problems discussed are reached at without being biased by personal (inclusive of the socio- cultural background) motives/ ideas. Needless to say, the subsidies by the government that the students have been enjoying in the form of their minimal fees also subtly warrants that they think not as individuals but as a collective whole, that is India. In purview of this argument, it could be established that the relevance of including such a subject "Business, Government and Society" in the Management curriculum is also fulfilled.

\section{Acknowledgments}

We would like to thank our students for their whole hearted support for this study as well as the fraternity of the institution for giving us this opportunity for research.

\section{References and Notes}

[1] Qualifications and Curriculum Authority, 1998, p. 57 as quoted in Badri, Al Said, "Teaching Controversial Issues in the Classroom", CERJ 5(1) 
[2] http://www.bbc.com/news/world-asia-india-35650616, accessed on 19.10.2017

[3] Parthasarathy, "India's Cultural Plural its Best Defence", 05 Nov, 2009, http://www.thehindu.com/opinion/op-ed/Indiarsquosculturalpluralism-its-best-defence/article16890340.ece

[4] Philippott, S. et al. Controversial issues: To teach or not to teach? That is the

[5] question! The Georgia Social Studies Journal, 2011: 1.1, pp. 32-44

[6] Hess, D. (2005). How do teachers political views influence teaching about controversial issues? Social Education 69 (Jan/Feb) 47-48.

[7] Westheimer, J. (2008). On the relationship between political and moral engagement. In F. Oser \& Citizenship Education Research Journal (CERJ), 5(1)83 W. Veugelers (Eds.), Getting involved: Global citizenship development and the sources of moral values (pp.17-30). Rotterdam: Sense.

[8] Law Commission of India (2002) 182nd Report

[9] Gazette of India (2013) Ministry of Law, Govt. of India, The Right To Fair Compensation And Transparency In Land Acquisition, Rehabilitation And Resettlement Act, 2013.

[10] Drew Stewart (2010) Revisiting The Great Transformation: Tata's Entry and Exit in West Bengal, pp 12-17, London School of Economics and Political Sciences.

[11] Banerjee, Abhijit Vinayak. et. al, (, 2007 ) Beyond Nandigram: Industrialisation in West Bengal

[12] Economic and Political Weekly p;1487 (April 28)

[13] Anusha Chari, Madhav Raghavanhttp (2011) Foreign Direct Investment in India's Retail Bazaar: Opportunities and Challenges, http://www.unc.edu/ achari/retail.pdf accessed on 19 Oct 2017.

[14] Donovan Linley, (2011) Merger Remedies and the WalmartMassmart case, Econex Trade Competition and Applied Economics, Research Note and Competition Tribunal, Walmart Decision, 29 June 2011, paragraph 99.

[15] Dunlosky, John, et.al. Improving Students' Learning With

[16] Effective Learning Techniques: Promising Directions From Cognitive and

[17] Educational Psychology, Psychological Science in the Public Interest, 2013: 14(1) 4-58 p. 7

[18] Prince, Michael. Does Active Learning Work: A Review of the Research, Journal of Engineering Education. 93(3), 223-231 (2004), pp. 4-5. 